\title{
Pattern and prevalence of smoking among students at King Faisal University, Al Hassa, Saudi Arabia
}

H.I. Al-Mohamed ${ }^{7}$ and T.T. Amin ${ }^{2}$

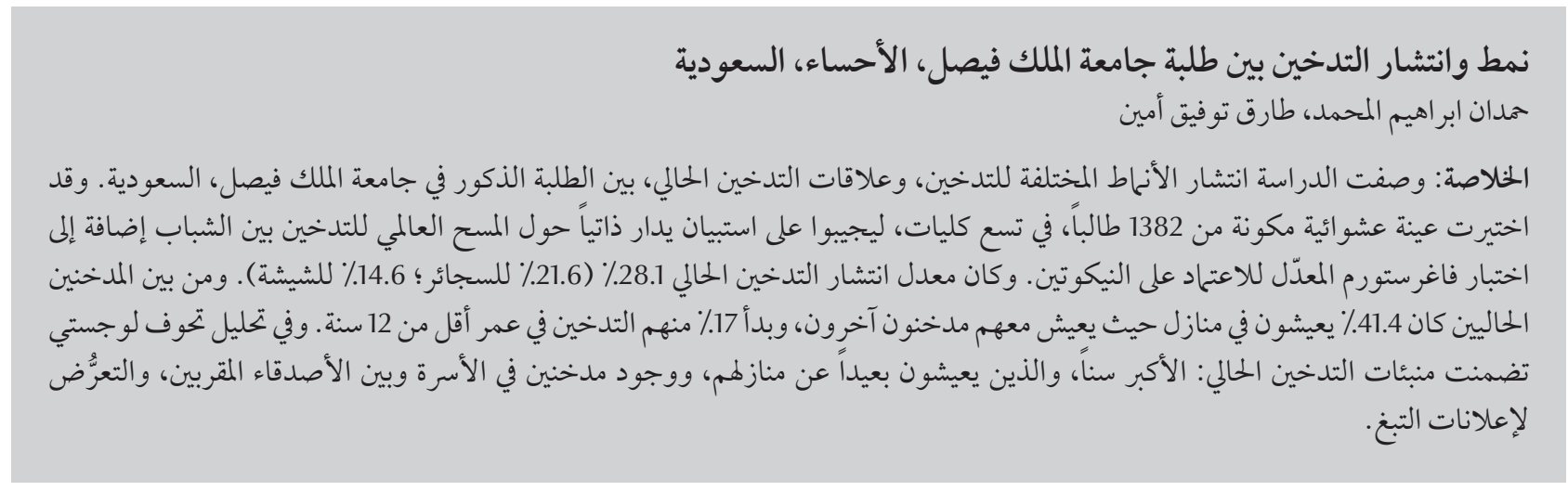

ABSTRACT The study describes the prevalence of different forms of smoking, and the correlates of current smoking, by male students of King Faisal University, Saudi Arabia. A random sample of 1382 students at 9 colleges answered a self-administered questionnaire based on the Global Youth Tobacco Survey plus the modified Fagerström Test for Nicotine Dependence. The prevalence of current smoking was 28.1\% (21.6\% for cigarettes, $14.6 \%$ for waterpipe). Of current smokers, $41.4 \%$ were living in homes where others smoke and $17.0 \%$ initiated smoking below age 12 years. In logistic regression analysis older age, living away from home, smoking by family and close friends and exposure to tobacco promotion were predictors of current smoking status.

\section{Caractéristiques et prévalence du tabagisme chez les étudiants de l'université Roi Fayçal d'Al Ahsa (Arabie saoudite)}

RÉSUMÉ Cette étude décrit la prévalence des différentes formes de tabagisme et les corrélats du tabagisme au moment de l'étude chez des étudiants de sexe masculin de l'université Roi Fayçal (Arabie saoudite). Un échantillon aléatoire de 1382 étudiants inscrits dans 9 facultés a répondu à un autoquestionnaire fondé sur l'enquête mondiale sur le tabagisme chez les jeunes et sur le test de Fagerström modifié sur la dépendance à la nicotine. La prévalence du tabagisme au moment de l'étude était de 28,1 \% (21,6 \% pour les cigarettes ; 14,6 \% pour la pipe à eau : parmi ces fumeurs, 41,4 \% vivaient avec d'autres fumeurs et 17,0 \% avaient commencé à fumer avant l'âge de 12 ans. Dans l'analyse de régression logistique, l'âge, le fait de vivre loin de chez soi, le tabagisme chez les membres de la famille et les amis proches, et l'exposition à la publicité en faveur du tabac étaient des facteurs prédictifs du tabagisme au moment de l'étude. 


\section{Introduction}

Smoking has been identified as the single most important cause of preventable morbidity and premature death [1]. Although many of the adverse health effects of tobacco occur later in life, smoking has health implications for young people [2] and is associated with other high-risk behaviours among young people including abuse of other drugs, fighting and high-risk sexual behaviour [3]. Each day, nearly 4800 adolescents smoke their first cigarette; of these, nearly 2000 will become regular smokers [4]. Smoking-related health problems are a function of the duration (years of smoking) and intensity (number of cigarettes/day); most adult smokers began to smoke or were already addicted before the age of 18 years [5]. While many adolescents want to quit smoking, only a small number of them succeed [6].

There has been a dramatic increase over the past decade in the numbers of college-age smokers [7]. Several studies report that the prevalence of smoking increases from the first year to the final year among university students, which underlines the fact that the early years at university are important for targeting anti-smoking activities [8,9]. Students who enter college as non-smokers are $40 \%$ less likely to begin smoking if they live in a smoke-free campus [10].

The World Health Organization has reported widely differing prevalences of smoking among young people in the Arab countries: 7\% in Oman, 18\% in Kuwait, 23\% in Iraq, 25\% in Saudi Arabia and Jordan, 31\% in Syrian Arab Republic, 43\% in Yemen and 53\% in Lebanon [11]. However, the trend and pattern of smoking as well as the quitting rate especially among college students are largely unknown in many of these countries. The objectives of the present study were to describe the pattern and prevalence of different forms of smoking among male students at King Faisal
University, Al Hassa, Saudi Arabia and to explore the possible correlates and/ or predictors of current smoking status.

\section{Methods}

This was a cross-sectional descriptive study.

\section{Setting and sample}

King Faisal University in Al-Hassa is located at the Eastern province of Saudi Arabia. The campus contains 9 colleges and the total population enrolled in the University according to registries for the academic year 2006-07 was 12400 ; the male population was 8200

A sampling frame of all students at the different colleges, of all grades and with male sex only was used for the purpose of sampling. Females were not included due to the traditions of Saudi Arabian society which restricts access to females by male researchers and the lack of female researchers at the time of the study. Using Epi-Info 2002 software, a total population of 8200 , assuming the prevalence of smoking from a similar study of $18 \%$ [12] and the worst acceptable prevalence was $16 \%$, applying a confidence level of $95 \%$, the total number of subjects required for our study was 1209; taking into consideration a non-response rate of about $15 \%$, the final sample size was estimated as 1390 students ( $16.9 \%$ of the enrolled students at the University).

A multistage proportionate sampling method was applied. The colleges were stratified according to the scope of specialty and number of enrolled students. A sampling fraction was calculated to select participants in relation the population in each college. For each college the students were chosen using a systematic random sampling technique from the available registries.

\section{Data collection}

Data were collected using an anonymous self-administered, modified Arabic version of the Global Youth Tobacco Survey questionnaire [13], with the addition of the modified Fagerström Test for Nicotine Dependence [14]. The final form of the questionnaire was field tested on 100 students from the medical college who were not part of the sample.

The questionnaire included the following items: sociodemographic data (age in years, college, year, current and permanent residence, living with parents or not); smoking within the household (who smoked, for how long, extent of smoking and quitting, if any); current smoking status; opinions about smoking behaviour; previous smoking experience; and pattern of smoking (type, age at initiation, duration in years, frequency of smoking and average cost per month). The modified Fagerström test is a widely used and validated 6-item questionnaire to assess severity of nicotine dependence [14], with scores ranging from 0 to 10 . A score $\leq 4$ suggests a low level of nicotine dependence, and a score $\geq 6$ usually indicates high dependence. Those who had not smoked in the previous 12 months or longer were asked to consider themselves as ex-smokers.

For each college, a series of visits was carried out by the investigators for selection of participants and orientation regarding the objectives, contents and confidentiality of data collection. Lecture halls in each college were used to deliver the necessary orientation session on the objectives and contents of the questionnaire while assuring the participants of the anonymity of their responses. The confidentiality of data was preserved according to the Helsinki declaration of bioethics.

\section{Data processing and analysis}

The data were revised and validated according to certain pre-determined 
criteria. Questionnaires with more than 2 items missing were discarded, a total of 69 forms. The response rate was 100\% in the different colleges with the exception of the college of education (84.3\%), agriculture (89.8\%) and management science (96.5\%). A pre-designed SPSS, version 12.0, file was used for data entry and data analysis. The following tests of significance were used as appropriate: chi-squared test of independence, Kruskall-Wallis and analysis of variance and Spearman rank order correlation coefficient. A logistic regression model was applied to determine the possible predictors and/or correlates of current smoking status of the respondents. $P \leq$ 0.05 was considered statitically significant.

\section{Results}

A total of 1382 male students were included, with age range $18-29$ years and mean age 20.9 [standard deviation (SD) 2.0] years (Table 1). Nearly onequarter of the students $(23.5 \%)$ were living away from home, the reasons for which were: education (95\%), marriage (4\%) or social reasons ( $1 \%$ ).

\section{Smoking prevalence and sociodemographics}

The prevalence of smoking among the students is shown in Table 2. For any type of tobacco $28.1 \%$ of respondents were current smokers, $37.4 \%$ ever smokers and $62.6 \%$ never smokers. For cigarettes, $21.6 \%$ were current smokers and $28.4 \%$ ever smokers, while for sheesha (traditional Arabic waterpipe) the corresponding prevalences were $14.6 \%$ and $16.7 \%$. Of the current smokers, $77.1 \%$ smoked cigarettes and $52.1 \%$ waterpipes.

Table 1 shows the sociodemographic characteristics of the respondents in relation to their current smoking status. Significantly more current smokers were in older age groups $20-<24$ years $(67.5 \%)$ and $24+$ years (15.7\%) compared with the total sample and with the never smokers and ex-smokers $(P<0.001)$. Students at the colleges of education, community services and agriculture had the highest prevalence of smoking compared with those at other colleges; the lowest prevalences were at the colleges of medicine and clinical pharmacy $(P<0.001)$. A significantly higher proportion of ever smokers (current and ex-smokers) (30.0\%) were living away from their parents compared with the never smokers $(19.7 \%)(P<$ 0.001).

\section{Environmental tobacco smoke}

Of the total respondents, $41.4 \%$ lived in homes where others smoked (Table 1); this was higher for current smokers (57.5\%) compared with ex-smokers (42.6\%) and never smokers (34.0\%) $(P$ $<0.001)$. Over half of all respondents (58.2\%) were exposed to tobacco in places other than home such as colleges, cafés and social gatherings ( $76.3 \%$ among current smokers, $33.6 \%$ of exsmokers and $26.2 \%$ of never smokers) $(P<0.001)$. The prevalence of smoking among any parents or relatives was also different ( $57.5 \%$ of current smokers versus $41.1 \%$ and $33.6 \%$ for ex-smokers and never smokers respectively) ( $P$ $<0.001)$. Current smokers had more close family members (father or brothers or both) who smoked (205/388 (53.4\%) than did ex-smokers (53/129, $41.1 \%)$ and never smokers (274/865, $31.7 \%)(P<0.001)$

Smoking among close friends was also different as $63.9 \%$ of current smokers reported that all or most of their friends were smokers compared with $24.8 \%$ and $15.8 \%$ of ex-smokers and never smokers respectively $(P<0.001)$.

\section{Patterns of smoking}

The duration of smoking among respondents ranged from 2 to 19 years, with a mean of 7.45 (SD 3.17) years. As regards the age of initiation of smoking among current smokers, $17.0 \%$ started below age 12 years $(4.6 \%$ at $10-11$ years, $6.7 \%$ at $8-9$ years and $5.7 \%$ at 7 years), $13.9 \%$ at $12-13$ years, $23.2 \%$ at $14-15$ years and $45.9 \%$ at $16+$ years. The age of initiation was significantly lower for those who smoked only cigarettes compared with those who smoked both cigarettes and waterpipe; $9.9 \%$ of them started at age $12-13$ years, $24.0 \%$ at $14-15$ years and $76.1 \%$ at $16+$ years $(P=0.012)$.

For cigarette smokers the mean monthly cost was 165.7 (SD 75.1) Saudi Arabian riyals (SR) (median 150 SR) and for waterpipe smokers it was 104.3 (SD 69.9) SR (median 100.0 SR). Home and college were the usual places for cigarette smokers to smoke (46.0\%), while waterpipe smokers smoked at special places such as cafés and restaurants.

\section{Nicotine dependence}

Of the current cigarette smokers, $47.0 \%$ had a nicotine dependence score of $\geq 6$ (high), 33.8\% scored 4-6 (moderate) and $19.2 \%$ scored $<4$ (minimal). The overall mean score on the modified Fagerström Test for Nicotine Dependence out of a maximum of 10 was 4.13 (SD $2.55)$ [ $95 \%$ confidence interval ( $\mathrm{CI})$ : 3.84-4.39] (Table 3, available in online version). Students at the colleges of computer science, community services and agriculture had the highest nicotine dependence scores, while the college of medicine students had the lowest score (Table 3). The mean number of cigarettes smoked per day was the highest among students of computer science and veterinary colleges $(P=0.029)$. There were significant differences between students in the different colleges in all the questions except about the item for the most difficult cigarette of the day to give up.

\section{Quitting behaviour}

Among the current smokers, about $60 \%$ had tried quitting, with a median of 3 


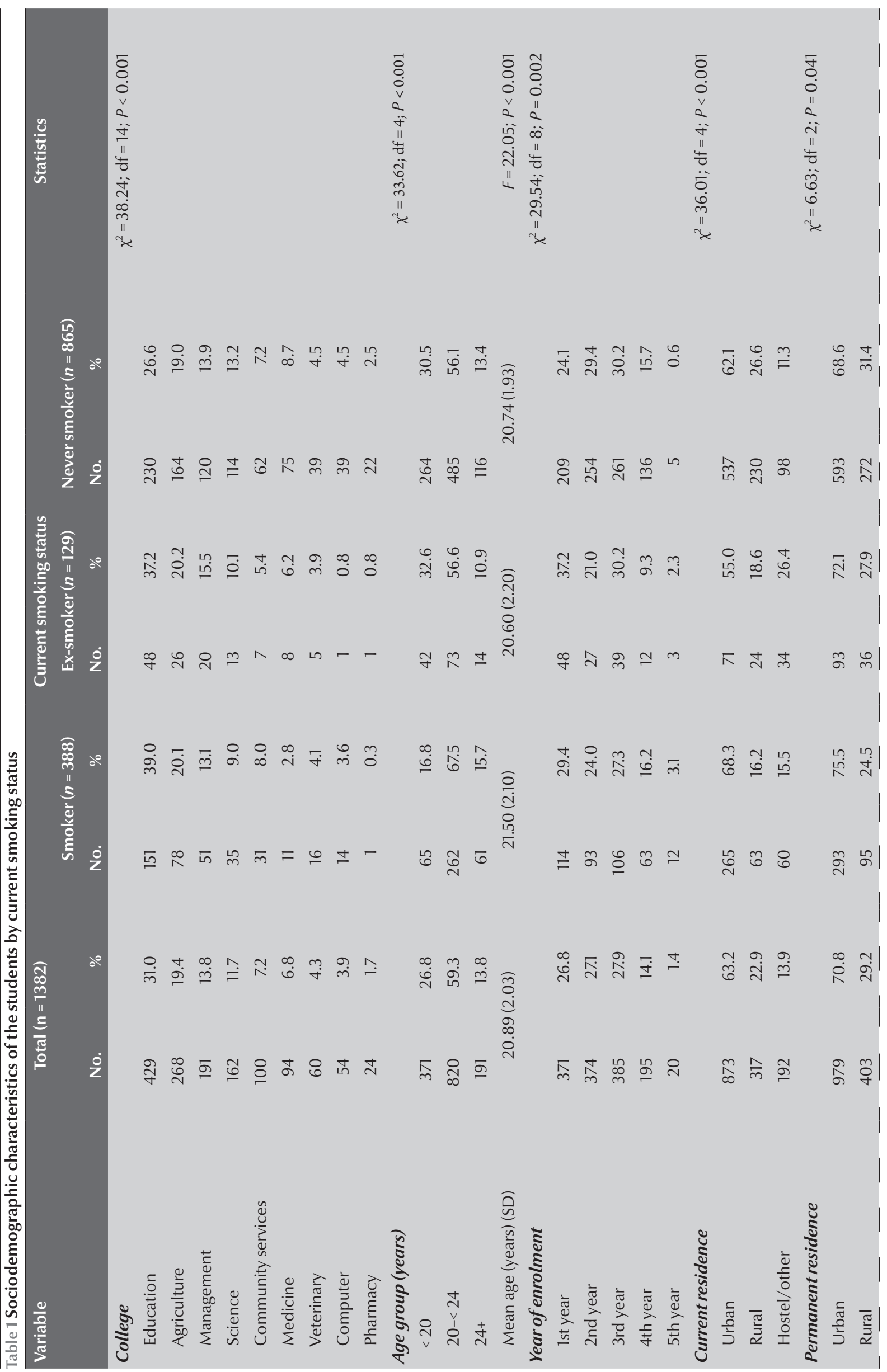



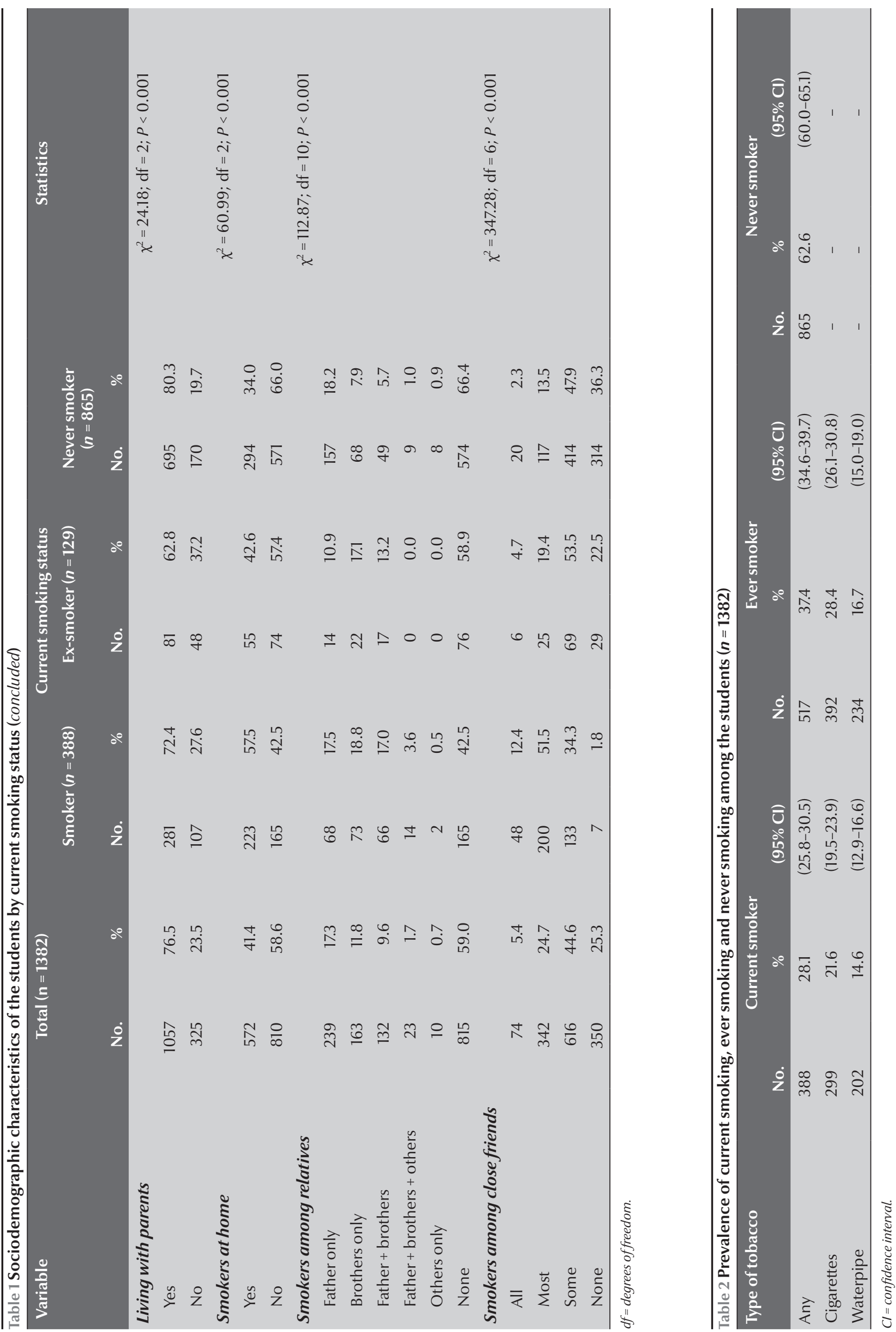
attempts, and $78 \%$ planned to quit in the near future. The primary motives for quitting were health, family pressure and restrictions, and other social reasons. Out of 388 current smokers 138 (35.6\%) had stopped smoking in the past, $76.1 \%$ for a period from $1-3$ months, $16.0 \%$ for $4-11$ months and $7.9 \%$ for 1 year or more.

\section{Knowledge and beliefs}

There were significant differences between smokers and non-smokers as regards their knowledge about the harms of both smoking and passive smoking and the effect of smoking on body weight $(P<0.001)$ (Table 4 , available in online version). In addition, there was a significant difference between smokers and non-smokers as regards receiving advice from family members on the harms of smoking. Concerning the participants' beliefs, there were significant differences between smokers and non-smokers that smokers have more friends and that smoking should be banned in public places $(P<0.001)$, but no difference in the belief that it was easy to quit smoking $(P=0.061)$; only about $25 \%$ of participants in both groups thought it was not easy to quit.

There were statistically significant differences between smokers and nonsmoker as regards having received free cigarettes or gifts during tobacco company promotions $(P<0.001)$. As regards students exposure to anti-smoking messages or smoking advertisements, $27.5 \%$ had seen anti-smoking messages in the media in the previous 30 days, while $54.2 \%$ had seen posters against smoking on several occasions at cultural and sports activities. However, 24.6\% had seen cigarette promotion advertisements in newspapers and magazines during the previous month.

\section{Smoking predictors}

Table 5 illustrates the logistic regression model of current smoking status against the possible correlates. The model explained $79.9 \%$ of cases. Older age was a risk factor for current smoking (OR $=2.57$ for age $20-<24$ years). Urban residence was also a risk factor. While residing in hostels/other residence was significant on univariate analysis it became insignificant in the multivariate model. Living with parents was protective against the adoption of smoking $(\mathrm{OR}=0.53)$; so too was having received parental and family advice against the hazards of smoking $(\mathrm{OR}=0.07)$. Having parents and other family members who smoked was a risk factor for smoking $(\mathrm{OR}=2.52)$, while having all or most close friends as smokers was an even greater risk $(\mathrm{OR}=6.86)$. Receiving free cigarettes through promotional campaigns of cigarettes companies was associated with smoking $(\mathrm{OR}=2.82)$; so too was receiving gifts with tobacco company logos $(\mathrm{OR}=2.28)$. Finally, exposure to high intensity media messages against smoking was protective of current smoking $(\mathrm{OR}=0.59)$.

\section{Discussion}

Although Saudi Arabia does not grow tobacco ormanufacture cigarettes, an average of 600 million SR (approximately US\$ 150 millions) are spent annually on tobacco [15]. No nationwide studies on the prevalence of tobacco have been performed and this, coupled with a lack of data regarding the pattern of smoking, may conceal serious tobacco-related problems [16]. The prevalence of current tobacco smoking in our students (28.1\%) was higher than rates reported in a previous study of students in Saudi Arabia (13.6\% among medical and $17.5 \%$ among students of education) [12], while a study conducted on male secondary school students in the central region of Saudi Arabia reported a similar prevalence (29.8\%) [17]. The reported prevalence among university/college students was $34.4 \%$ in Kuwait [18], $24.8 \%$ (males) in Syrian Arab Republic [19] and 22.1\% (males) in Turkey [8].
These figures can be compared with prevalences ranging from $5.5 \%$ to $20 \%$ among adolescents in some countries of the European Union and Canada [20].

Many people consider that waterpipe smoking is less harmful than cigarettes because they believe that the water filters out harmful substances. Waterpipes do not contain less nicotine than cigarette smoke and have more carbon monoxide [21]. Our study revealed a higher percentage of current smokers used waterpipes (52.1\%) than male students in other countries in the region (43.6\% in Saudi Arabia [12], $24.6 \%$ in Kuwait [22] and 25.5\% in Syrian Arab Republic [23]). This could be explained by the increasing popularity of waterpipe smoking. The widespread attention focused on the dangers of cigarette smoking, coupled with the stigma associated, might unintentionally encourage waterpipe smoking [22].

Data show that the proportion of adolescents who smoke increases with age $[24,25]$. Also, adolescents who start to smoke early are more likely to continue smoking as adults [26]. We found a negative association between smoking status and age which contradicts the first statement, probably because the age range of the study sample was too narrow to demonstrate such an association. Age at initiation in our study (66.5\% initiated below age 16 years) was lower than in another similar study in Saudi Arabia where about 59\% started smoking at or above the age of 18 years [12], whereas in another study in secondary schools $83.7 \%$ of the current smokers started at age 15 years or below [17]. A study in the USA reported the mean age of initiation to be 18.3 years among medical and nursing students [27].

Our results show that the prevalence of smoking varied across students at different colleges within the same university, which is consistent with other studies in Saudi Arabia [12] and 


\begin{tabular}{|c|c|c|c|c|c|c|}
\hline \multirow[t]{2}{*}{ Covariates } & \multicolumn{2}{|c|}{ Smoking status } & \multicolumn{4}{|c|}{ Multivariate logistic regression model } \\
\hline & $\begin{array}{l}\text { Current } \\
\text { smoker } \\
(n=388)\end{array}$ & $\begin{array}{c}\text { Non- } \\
\text { smoker }^{\mathrm{a}} \\
(n=994)\end{array}$ & $\beta$ & SE & OR $(95 \% \mathrm{Cl})$ & $P$-value \\
\hline \multicolumn{7}{|l|}{ Age group (years) } \\
\hline$<20$ & 65 & 306 & & & $1^{b}$ & $<0.001$ \\
\hline $20-<24$ & 262 & 558 & 0.945 & 0.260 & $2.57(1.56-4.28)$ & $<0.001$ \\
\hline $24+$ & 61 & 130 & 0.406 & 0.224 & $1.50(0.97-3.38)$ & 0.070 \\
\hline \multicolumn{7}{|l|}{ Current residence } \\
\hline Urban & 265 & 608 & & & $1^{b}$ & 0.004 \\
\hline Rural & 63 & 254 & -0.735 & 0.293 & $0.48(0.27-0.86)$ & 0.013 \\
\hline Hostel/other & 60 & 132 & -0.236 & 0.315 & $0.61(0.31-0.80)$ & 0.454 \\
\hline \multicolumn{7}{|l|}{ Living with parents } \\
\hline Yes & 281 & 776 & -0.632 & 0.237 & $0.53(0.33-0.85)$ & 0.008 \\
\hline No & 107 & 218 & & & & \\
\hline \multicolumn{7}{|l|}{ Smokers at home } \\
\hline Yes & 223 & 344 & -0.923 & 0.147 & $2.52(1.89-3.36)$ & $<0.001$ \\
\hline No & 165 & 650 & & & & \\
\hline \multicolumn{7}{|c|}{ Smokers among close friends } \\
\hline All/most & 248 & 150 & 1.926 & 0.147 & $6.86(5.14-9.16)$ & $<0.001$ \\
\hline Few/none & 140 & 826 & & & & \\
\hline \multicolumn{7}{|c|}{ Received parental advice against smoking } \\
\hline Yes & 285 & 634 & -0.358 & 0.158 & $0.70(0.51-0.95)$ & 0.024 \\
\hline No & 103 & 360 & & & & \\
\hline \multicolumn{7}{|c|}{ Received free cigarettes from tobacco company promotion } \\
\hline Yes & 156 & 40 & 1.038 & 0.157 & $2.82(2.12-3.76)$ & $<0.001$ \\
\hline No & 232 & 954 & & & & \\
\hline \multicolumn{7}{|c|}{ Received gift with tobacco company logo (wallet, pens, shirts) } \\
\hline Yes & 252 & 315 & 0.824 & 0.266 & $2.28(1.35-3.84)$ & 0.002 \\
\hline No & 136 & 679 & & & & \\
\hline \multicolumn{7}{|c|}{ Exposed to media messages against smoking } \\
\hline Many & 120 & 261 & -0.534 & 0.158 & $0.59(0.43-0.80)$ & $<0.001$ \\
\hline Few or did not follow & 268 & 733 & & & & \\
\hline
\end{tabular}

${ }^{a}$ Ex-smokers + never smokers; ${ }^{b}$ Reference group.

$S E=$ standard error; $O R=$ odds ratio; $C I=$ confidence interval.

the USA [27]. Gliksman et al. found that students in arts and social sciences programmes were $2-3$ times more likely to be current daily smokers than were students enrolled in a science programme [28]. We found higher rates of smoking by students at the colleges of education, community services and agriculture. The intensity of physical addiction to nicotine as measured by the Fagerström test [28] also showed higher dependency among students at these colleges.
The mean Fagerström score among all medical students in our study [2.90 (SD 1.97)] was higher than among medical students in a study in the USA [2.3 (SD $0.8)][27]$.

Smoking by parents and sibling seems to be important in the initiation as well as the continuation of smoking. Bauman et al. found that 12-14-yearolds whose parents currently smoked were almost twice as likely to smoke as those whose parents had never smoked
[29]. Kandel and Wu found that both maternal smoking and the quality of parent-child interaction influenced the current smoking status among adolescents [30]. These finding are consistent with our study as current smokers had twice the risk when relatives, especially parents and siblings, were smokers.

Friends' behaviour and attitudes have also been shown in a large number of studies to be a particularly powerful force in shaping behaviour [31]. Peer 
smoking seemed to be the most important factor influencing smoking behaviour of our respondents. Bawazeer et al. [32] and Botvin et al. [33] reported similar findings in younger populations. A study in the Syrian Arab Republic demonstrated that about half of male current smokers were introduced to smoking by a friend and they smoked because their friends did so [23]. Hahn et al. found that $60 \%$ of adolescent aged 11-17 years had first smoked, and $72 \%$ had most recently smoked, with a close friend [34]. Mohammed et al. in Kuwait found that about half of male waterpipe smokers and $70 \%$ of female waterpipe smokers reported that waterpipe smoking was either accepted or very much accepted by their friends, and both males and females tended to have friends whose behaviour and attitudes reflected their own behaviour [22].

Parental guidance and living with parents was protective against taking up smoking in our study. Gfroerer et al. also showed that among a sample of USA college students, those who lived with their parents were less likely to have smoked in the last month compared to students who did not [35]. These findings are further supported by Adlaf et al. who found that post-secondary students who resided off campus without their family had a higher rate of daily smoking than those living in university housing and those living with their parents [36].

It has been hypothesized that the tobacco industry's targeted marketing strategies have contributed to the observed increase in cigarette use among post-secondary students [37]. In Saudi Arabia, tobacco advertising and promotion are prohibited in the local media and smoking is not allowed in government buildings or on domestic flights. However, there is no close monitoring of compliance [38] and in our study $24.6 \%$ of respondents had seen cigarette promotion advertisements in newspapers and magazines during the previous month. Another study among secondary-school students in Saudi Arabia revealed that about 66\% had seen pro-cigarette advertisements on billboards, $73 \%$ had seen advertisements in magazines or newspaper, $12 \%$ had an object with cigarette logo and $28 \%$ had been offered free cigarettes by company representatives [17]. Promotional events reinforce brand visibility, allow the industry to reach specific target groups and generate names for future marketing efforts [39]. In addition,
Rigotti et al. found that the distribution of free cigarettes and attendance of tobacco company sponsored events was strongly associated with current smoking after adjusting for demographic factors $(\mathrm{OR}=1.75)[40]$.

There were some limitations to the study. Only male students were included in the study as the access to females was difficult. Although anonymity was guaranteed for data collection, smoking is socially unacceptable in the Saudi Arabian community, and therefore the prevalence of smoking by self-reporting may have been underestimated.

\section{Conclusion}

Smoking among students in Saudi Arabia seems to be higher in terms of prevalence and intensity as compared to those in developed countries. Most of the current smokers in our study were highly nicotine dependent with significant variation across colleges. Parents, siblings and peers were the most important predictors of smoking behaviour among the students. Concerns are raised about role of promotional strategies and the media in the initiation and progression of smoking behaviour among this group.

\section{References}

1. Chapter 5. Combating the tobacco epidemic. In: World health report 1999. Making a difference in people's lives. Geneva, World Health Organization, 1999.

2. Symptoms of substance dependence associated with use of cigarettes, alcohol, and illicit drugs-United States, 1991-1992. Morbidity and mortality weekly report, 1995, 44(44):830-831, 837-839.

3. Health situation in the South-East Asia Region, 1998-2000. New Delhi, World Health Organization Regional Office for SouthEast Asia, 2002.

4. Adolescent smoking statistics [online factsheet]. American Lung Association. (http://www.lungusa.org/site/c. dvLUK9O0E/ b.4061173/apps/s/content.asp?ct=66697, accessed 13 May 2009).

5. Youth and tobacco: preventing tobacco use among young people: a report of the Surgeon General. Atlanta, Georgia, Centers for Disease Control and Prevention, Center for Health Promotion, 1994.
6. Lamkin L, Houston TP. Nicotine dependency and adolescents: preventing and treating. Primary care, 1998, 25:123-35.

7. Houston TP, Kolbe LJ, Eriksen MP. Tobacco-use cessation in the 90s-not "adults only" anymore. Preventive medicine, 1998, 27:A1-2.

8. Aslan D et al. Prevalence and determinant of adolescent smoking in Ankara, Turkey. Turkish journal of cancer, 2006, 36(2):49-56.

9. Yegenoglu $\mathrm{S}$ et al. What is behind smoking among pharmacy students: a quantitative and qualitative study from Turkey? Substance use and misuse, 2006, 41:405-14.

10. Special Report of the Health Council Concerning a TobaccoFree Campus. Presented at the 614th Regular Meeting of the Faculty Senate, 2003 (Sen. Doc 03-014) (http://www.umass. edu/senate/fs_docs/SEN_DOC_NO_03-014_TOBACCO_ FREE.pdf, accessed 10 November 2009).

11. Economics of Tobacco for the Middle East and North Africa (MNA) Region. Regional Report: Middle East and North Africa (MNA),yy May 182001 (http://siteresources.worldbank.org/ 
INTETC/Resources/375990-1089913200558/MiddleEastandNorternAfrica.pdf, accessed 15 November 2009).

12. Abolfotouh MA et al. Smoking habits of King Saud University students in Abha, Saudi Arabia. Annals of Saudi medicine, 1998, 18:212-6.

13. GYTS: Core Questionnaire. Centers for Disease Control and Prevention [website] (http://www.cdc.gov/tobacco/global/ GYTS/questionnaire.htm, accessed 15 June 2009).

14. Fagerström KO, Schneider NG. Measuring nicotine dependence: a review of the Fagerström tolerance questionnaire. Journal of behavioral medicine, 1989, 12:159-82.

15. Foreign trade statistics in Saudi Arabia. Riyadh, Ministry of Finance and National Economy, Saudi Arabian Central Department of Statistics, 1985-1995.

16. Jarallah J et al. Prevalence and determinants of smoking in three regions of Saudi Arabia. Tobacco control, 1999, 8:53-6.

17. Al Damegh SA et al. Cigarette smoking behavior among male secondary school students in the central region of Saudi Arabia. Saudi medical journal, 2004, 25:215-9.

18. Moody PM al. Factors associated with the initiation of smoking by Kuwaiti males. Journal of substance abuse, 1998, 10:375-84.

19. Maziak $W$ et al. Characteristics of smoking and quitting among university students in Syria. Preventive medicine, 2004, 39:330-6.

20. Hublet $\mathrm{A}$ et al. Smoking trends among adolescents from 1990 to 2000 in ten European countries and Canada. BMC public health, 2006, 6:280.

21. Zahran FM, Ardawi MS, Al Fayez S. Carboxyhaemoglobin concentration in smokers of sheesha and cigarette in Saudi Arabia. British medical journal, 1985, 291:1768-70.

22. Mohammed HR, Newman IM, Tayeh R. Sheesha smoking among a sample of future teachers in Kuwait. Kuwait medical journal, 2006, 38(2):107-13.

23. Maziak W et al. Prevalence and characteristics of nargile smoking among university students in Syria. International journal of tuberculosis and lung disease, 2004, 8:882-9.

24. Bilir N, Dogan BG, Yildis AN. [Smoking behaviour. Publication No. 7.] Ankara, Hacettepe Public Health Foundation, 1997 [in Turkish].

25. Smoking 101. Pennsylvania Tobacco Cessation and Intervention Project [website] (http://www.paahec.org/professional development/tobacco/healthcare/health_01.asp, accessed 15 June 2009).
26. Rend DJ, McNeill, Glynn TJ. Reducing the prevalence of smoking in youth in Western countries: an international overview. Tobacco control, 1995, 4:266-77.

27. Ashwin AP et al. A comparison of smoking habits among medical and nursing students. Chest, 2003, 124(4):1415-20.

28. Rustin TA. Assessing nicotine dependence. American family physician, 2000, 62(3):209-20.

29. Bauman KE et al. Effect of parental smoking classification on the association between parental and adolescent smoking. Addictive behaviours, 1990, 15(5):413-22.

30. Kandel D, Wu P. The contributions of mothers and fathers to the intergenerational transmission of cigarette smoking in adolescence. Journal of research on adolescence, 1995, 52:225-52.

31. Urberg KA et al. A two stage model of peer influence in adolescent substance use. Individual and relationship-specific differences in susceptibility to influence. Addictive behaviours, 2003, 28:1243-56.

32. Bawazeer AA, Hattab AS, Morales E. First cigarette smoking experience among secondary school students in Aden, Republic of Yemen. Eastern Mediterranean health journal, 1999, 5:440-9.

33. Botvin GJ et al. Correlates and predictors of smoking among black adolescents. Addictive behaviours, 1992, 17(2):97-103.

34. Hahn G et al. Adolescents' first and most recent use situations of smokeless tobacco and cigarettes: similarities and differences. Addictive behaviours, 1990, 15(5):439-48.

35. Gfroerer JC, Greenblatt JC, Wright DA. Substance use in the US college-age population: differences according to educational status and living arrangement. American journal of public health, 1997, 87:62-5.

36. Adlaf EM et al. Cigarette use among Canadian undergraduates. Canadian journal of public health, 2003, 94:22-4.

37. Hammond D et al. Tobacco on campus: industry marketing and tobacco control policy among post-secondary institutions in Canada. Tobacco control, 2005, 14:136-40.

38. Tobacco or health: a global status report. Geneva, World Health Organization, 1997:260-1.

39. Hammond D. Smoking behavior among young adults: beyond youth prevention. Tobacco control, 2005, 14:181-5.

40. Rigotti NA, Moran SE, Wechsler H. US college students' exposure to tobacco promotions: prevalence and association with tobacco use. American journal of public health, 2002, 95(1):138-44.

\section{Note from the Editor}

We wish to draw the kind attention of our potential authors to the importance of applying the editorial requirements of EMHJ when preparing their manuscripts for submission for publication. These provisions can be seen in the Guidelines for Authors, which are available online at http:/ / www.emro.who.int/emhj.htm, and are published at the end of the first issue of each volume. We regret that we are unable to consider papers that do not conform to the Guidelines. 